\title{
THE INCIDENCE OF DEEP VENOUS THROMBOSIS IN PARAPLEGICS
}

\author{
By R. S. Philipps, M.B., F.R.C.S. \\ Department of Orthopaedics, Princess Margaret Rose Hospital, Edinburgh
}

MURLEY (1950), studying I 763 surgical cases, found the overall incidence of fatal pulmonary embolism to be o. I per cent. and the incidence of non-fatal embolism to be five to six times greater. Statistics establishing the incidence of deep venous thrombosis are apt to be misleading because the symptoms of the disease are protean and often slight and the criteria for diagnosis somewhat variable, depending much upon the observer. Nevertheless, the incidence of occurrence of pulmonary embolism does reflect the relatively high incidence of deep venous thrombosis in the lower limbs.

Before assessing the incidence of thrombosis in paraplegics it would be of value to review the factors thought to be concerned in the aetiology of this complication.

Dodd and Cockett (1956) are emphatic in stating that the most important single factor is the occurrence of a sluggish venous stream. Of greatest importance in venous stasis is a weakened or absent calf muscle pump. Wakin et al. (1948) tested the effects of percutaneous electrical stimulation on the circulation in normal and paralysed lower limbs. They noted that such stimulation increased the blood flow by over Ioo per cent. in normal limbs and in limbs in spastic paraplegia, but produced no increase in limbs in flaccid paraplegia. Muscle flaccidity is most marked in complete paraplegics though there exist intermittent spasms in response to noxious stimuli. Such spasms can have no effective pump action because of their infrequency. Gravity in the upright position contributes to stasis. Only when the lower limbs are elevated can gravity aid venous return. The convalescent paraplegic, spending much time in a wheel chair, cannot utilise the force of gravity in aiding venous return.

Negative intrathoracic pressure aids venous flow to the heart. Patients with cervical lesions have initially, at least, a flaccid paralysis of the intercostal muscles. Consequently it is presumed that the negative suction force is diminished.

Rowden Foote (1960) states that any form of tissue injury releases a thrombokinase which facilitates local clotting. It appears unlikely that this thrombokinase release is in any way increased in paraplegics. Trauma to the vein intima may however be more repetitive in paraplegics because of the absence of normal sensation. Prolonged calf pressure as a result of the absence of protective motor response in the early stages after cord injury enhances the likelihood of intimal damage.

Increased blood viscosity has been incriminated in the aetiology of thrombosis but there is no reason to suspect that in paraplegics the blood viscosity is different than it is in other surgical patients. General debility, too, is a proven factor in the causation of thrombophlebitis. Paraplegics only too often become anaemic and wasted.

Deep venous thrombosis is far more common in those over 40 years of age. Pratt (1949) reported that 80 per cent. of his patients were in this age group.

More specifically, Whitteridge (1954), in investigating the cardiovascular disturbances in paraplegics, has shown that there is significant arterial, capillary 
and venous tone. Thus, though the skeletal muscle is flaccid the smooth muscle in veins is not. The venous wall, however, is not sufficiently muscular to compensate for the absent muscle pump.

\section{MATERIAL}

Twenty-five paraplegic patients, i.e. 50 limbs, have been investigated clinically and radiologically to ascertain the incidence of deep venous thrombosis. Twentyfour of these were male and only one female. The average age at the time of investigation was 39.5 years.

The cause of paraplegia and the level of the lesion are shown in Table I.

TABLE I

\begin{tabular}{|c|c|c|c|c|}
\hline \multicolumn{3}{|c|}{ TRAUMA } & & $\begin{array}{c}\text { TRANSVERSE } \\
\text { MYELITIS }\end{array}$ \\
\hline Cervical & Mid-dorsal & Dorso-lumbar & Lumbar & \\
\hline 6 & 2 & I5 & I & I \\
\hline
\end{tabular}

Table II shows the degree of motor power in the lower limbs:

TABLE II

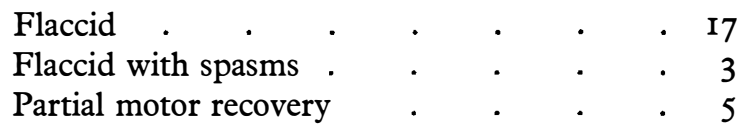

By reference to the patient's case notes and by physical examination, Table III was compiled to demonstrate the salient points in reference to the possibility of the existence of a previous deep venous thrombosis, or its sequelae of oedema, induration and ulceration.

\section{TABle III}

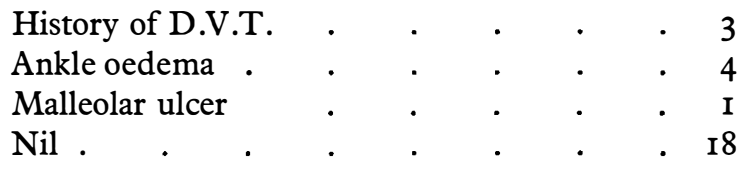

Before describing the radiological findings in these paraplegics, the following description of the normal phlebogram is given (Bauer, I942):

I. The peroneal and posterior tibial veins, either single or double trunks, are well filled. The beaded outline is due to the normal valve pattern.

2. The peroneal vein lies deeply in the calf, on the interosseous membrane. The posterior tibial lies posterior to the tibia. Usually, thick walled branches drain to these.

3. The anterior tibial vein is inconstant in its filling.

4. The popliteal vein, large and well filled, is a direct continuation of peroneal and posterior tibial veins. In its lower part filling may be poor or absent because 
the soleus muscle at its fibrous origin from the soleal line, compresses the dye from the vein (positive soleal sign).

5. The internal and external saphenous veins and their subcutaneous tributaries are poorly filled or inconstant. (Figures I and 2 demonstrate the normal phlebogram.)

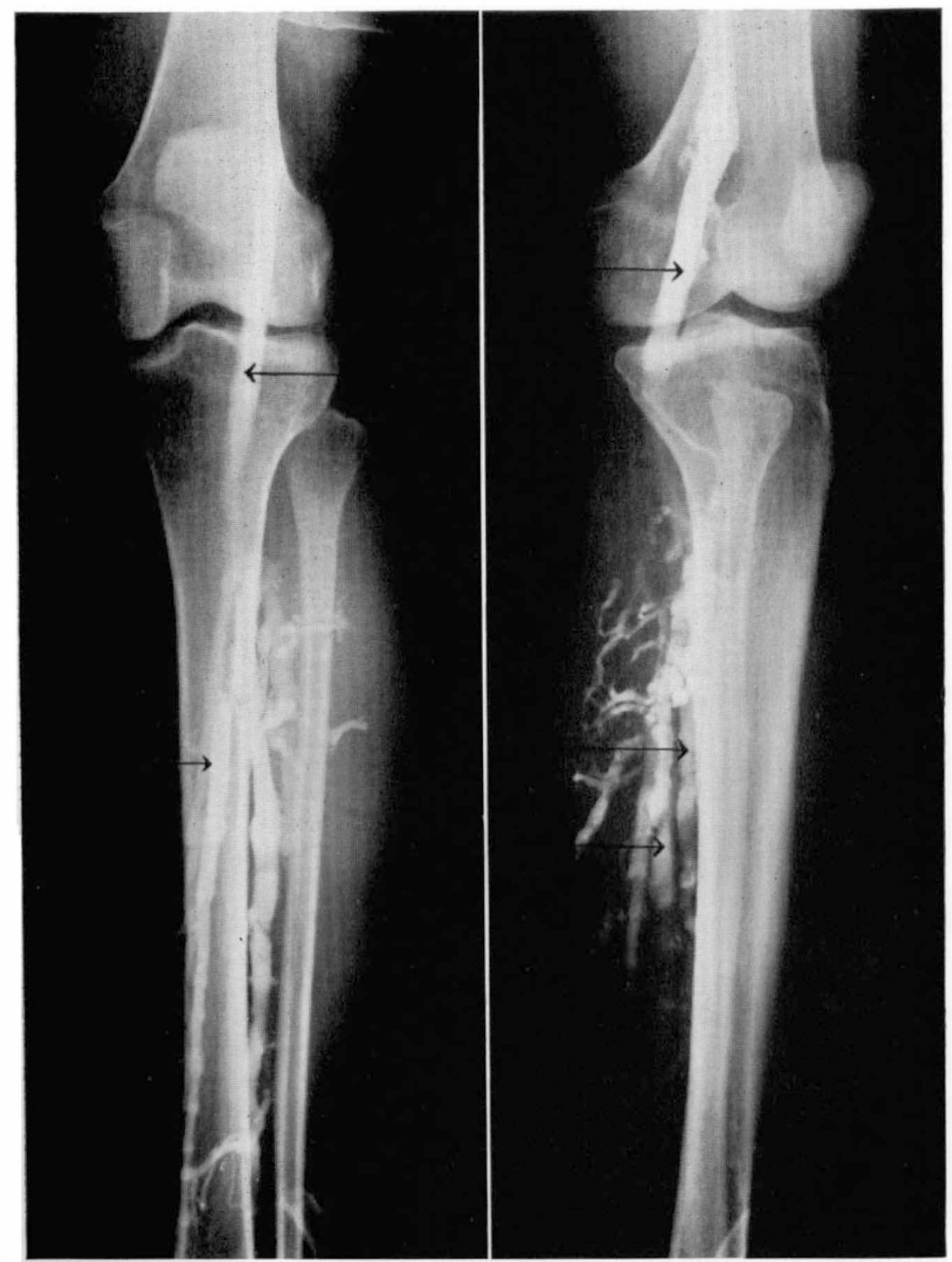

FIGS. I and 2

Antero-posterior and lateral of normal venogram. The posterior tibial and peroneal veins are draining to the popliteal. The apparent filling defect (soleal sign) is seen at the commencement of the popliteal vein. 
The interpretation of the abnormal venogram is fraught with difficulties. However, Bauer (1942) is convinced that complete absence of deep vein filling means occlusion by thrombus. A thrombosed vein, when recanalised, has no valvular pattern. Local dilatation of a segment with loss of valve pattern probably signifies recanalisation, but such a diagnosis cannot be made with certainty.

Since Dos Santos (1938) established the diagnostic possibilities of phlebography, the injection of radio-opaque dye by the intravenous route has given satisfactory films. However, the technique of this procedure necessitates the use of two tourniquets. The thigh tourniquet allows damming back of dye to ensure adequate filling. The malleolar tourniquet is used so that on injecting dye into a vein on the dorsum of the foot, it is forced through perforating channels into the deep venous system.

The malleolar tourniquet, however, is not always effective in preventing filling of the saphenous system; consequently a method of dye injection into the deep system directly has been sought. The technique of intraosseous phlebography, whereby dye is introduced into the medullary cavity of bone, has been firmly established by Schobinger (1960). Although the resultant phlebograms give the required information, the procedure has its disadvantages, not the least of which is the need for general anaesthesia. Fortunately, this can be dispensed with in paraplegics. Strong thick needles, even a trocar and cannula, have been used to penetrate the cortex of normal healthy bone. In paraplegics, the thin walled, osteoporotic cortex of lower tibia, and less often, the calcaneum, is readily penetrated by a routine aspiration needle, size $15 \mathrm{G}$.

The methods of phlebography used in this investigation have been both intravenous and intraosseous. The latter has been used when oedema has obscured dorsal veins or when muscle spasms have been severe enough to prevent successful venepuncture. Twenty millilitres per limb of 45 per cent. Hypaque is the radioopaque dye used in this phlebographic study.

Nineteen patients, i.e. 38 limbs, showed no evidence of deep venous thrombosis. Twenty-nine of these limbs, however, were abnormal in that the soleal sign was absent. In the six patients who showed evidence of previous thrombosis, four further limbs had an absent soleal sign. In Io limbs the soleal sign was present. Table IV relates these findings to degree of muscle power:

TABLE IV

\begin{tabular}{|c|c|c|}
\hline & Soleal sign - ve & Soleal sign + ve \\
\hline $\begin{array}{l}\text { Flaccid } \\
\text { Flaccid with spasms } \\
\text { Partial recovery (calf muscles } \\
\quad \text { grade I-3) }\end{array}$ & $\begin{array}{r}28 \\
4 \\
\mathrm{I}\end{array}$ & $\begin{array}{l}6 \\
0\end{array}$ \\
\hline
\end{tabular}

In six patients, seven limbs were found at phlebography to show evidence of deep vein block, i.e. evidence of previous thrombosis. The average age of this group of patients was 48.5 years in contrast to those in whom the deep veins were patent when the average was 36.6 years.

In four of these six patients, paraplegia had existed for less than I8 months, 
but in the three with definite clinical evidence of deep venous thrombosis, this was apparent within five weeks of injury. In five patients, flaccidity in the lower limb was complete, while in the sixth, almost complete motor recovery had occurred after one week.

Table $\mathrm{V}$ relates the clinical evidence of previous thrombosis to the phlebographic picture of its effects.

TABLE V

\begin{tabular}{|c|c|c|c|c|c|}
\hline \multicolumn{3}{|c|}{ Patient } & $\begin{array}{l}\text { History of } \\
\text { D.V.T. }\end{array}$ & $\begin{array}{l}\text { Malleolar ulceration } \\
\text { (past or present) }\end{array}$ & $\begin{array}{c}\text { Ankle } \\
\text { oedema }\end{array}$ \\
\hline Case I. J. T. . & & . & + & - & + \\
\hline Case 2. R. G. & & . & + & - & - \\
\hline Case 3. M. T. & & . & - & - & - \\
\hline Case 4. D. S. . & & . & + & - & + \\
\hline Case 5. A. McK. & & . & - & - & + \\
\hline Case 6. G. D. & & . & - & - & - \\
\hline
\end{tabular}

\section{CASE HISTORIES}

Case I. J. T. Male, 57 years old, fell from a tractor on I2 January I960 and immediately complained of loss of power and sensation in the lower limbs. Clinically and at myelography a diagnosis of central traumatic disc prolapse at Dio-I I was made. This was confirmed at laminectomy when the prolapse was removed on 24 January 1960. Within a week motor recovery was apparent in thigh and calf bilaterally. Sensory recovery, too, was proceeding. On I4 February I960 the patient complained of severe pain in the left calf which felt warm, tender and swollen. A diagnosis of deep venous thrombosis was made and anticoagulants commenced. Symptoms and signs settled within two weeks. When examined on 6 December 196I the patient was symptom free, but there was a little oedema of the left ankle, though no ulceration. At intravenous phlebography the deep veins of the right calf were normal but those of the left failed to fill, demonstrating evidence of previous thrombosis and inadequate recanalisation (figs. 3 and 4).

Case 2. R. G. Male, 70 years old, was knocked over by a motor vehicle on 30 July I 955 so sustaining paraplegia due to fracture dislocation of the 5 th dorsal vertebra. The initial treatment was conservative. Paraplegia was complete and has remained so. On I5 August I955 he developed clinical evidence of a deep venous thrombosis in the left calf. Anticoagulants were given for an unspecified length of time. On 6 December I96I clinical examination of the lower limbs confirmed the flaccid paraplegia. There was no oedema, induration or ulceration. Intravenous phlebograms showed normal deep veins on the left but on the right the calf veins had failed to fill. This was evidence of previous silent thrombosis. Figures 5 and 6 demonstrate this patient.

Case 3. M. T. Male, 56 years old, sustained, in 1944, a gunshot wound to the spine with resulting complete flaccid paraplegia from the level of Ioth dorsal vertebra downwards, which has persisted. Consequent upon this injury he developed, over the years, renal calculi and decubitus ulcers but there was never any clinical evidence of having sustained a deep venous thrombosis. On I9 April 1962 there was no evidence of previous malleolar ulceration; nor was there any ankle oedema. At phlebography the deep veins of the left calf failed to fill although those on the right were normal. Figures 7 and 8 show the evidence of his previous deep venous thrombosis. 


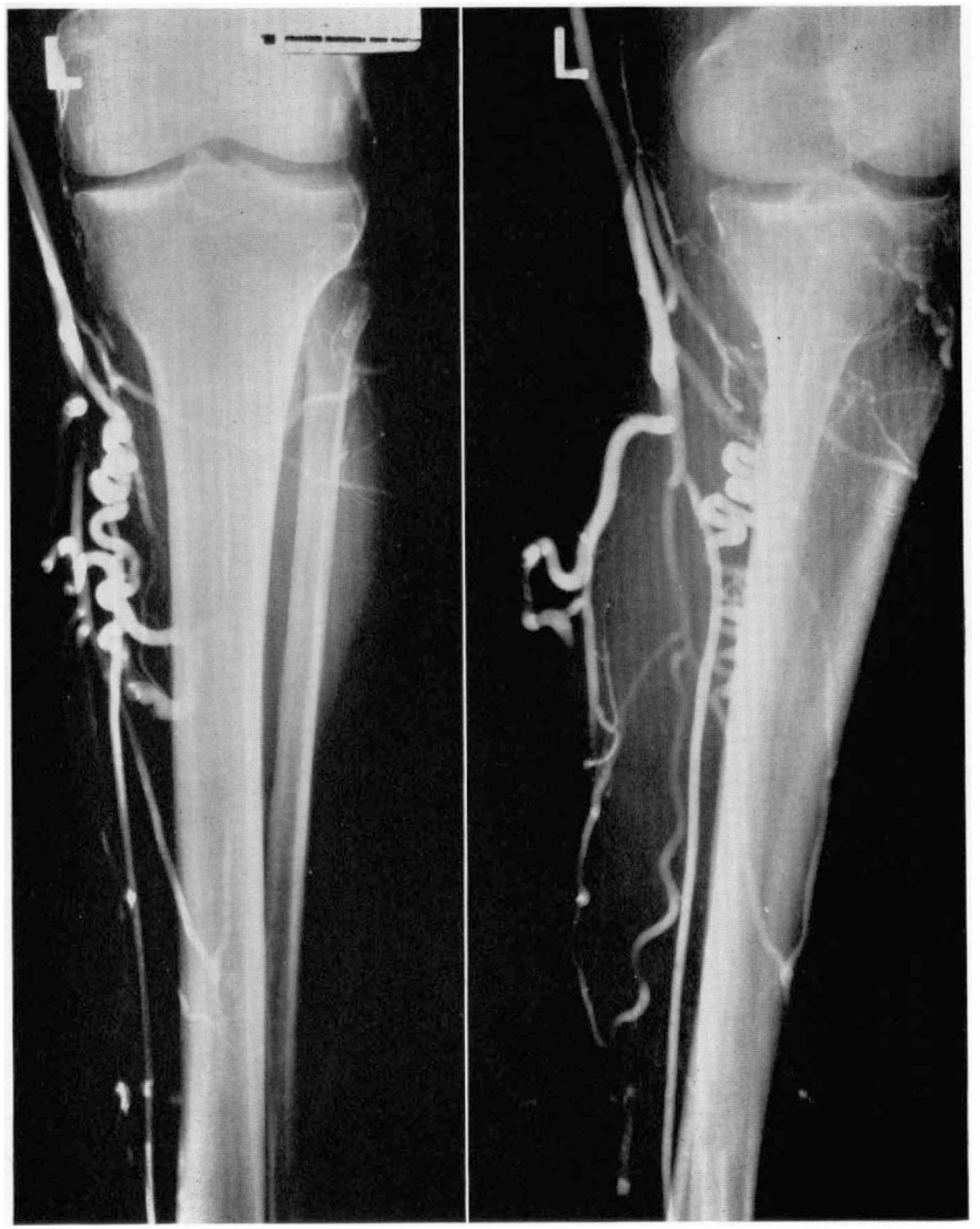

FIGs. 3 and 4

Antero-posterior and lateral views of Case I. The phlebogram of the left leg shows no filling in the deep veins, with varicosity of the saphenous systems. 


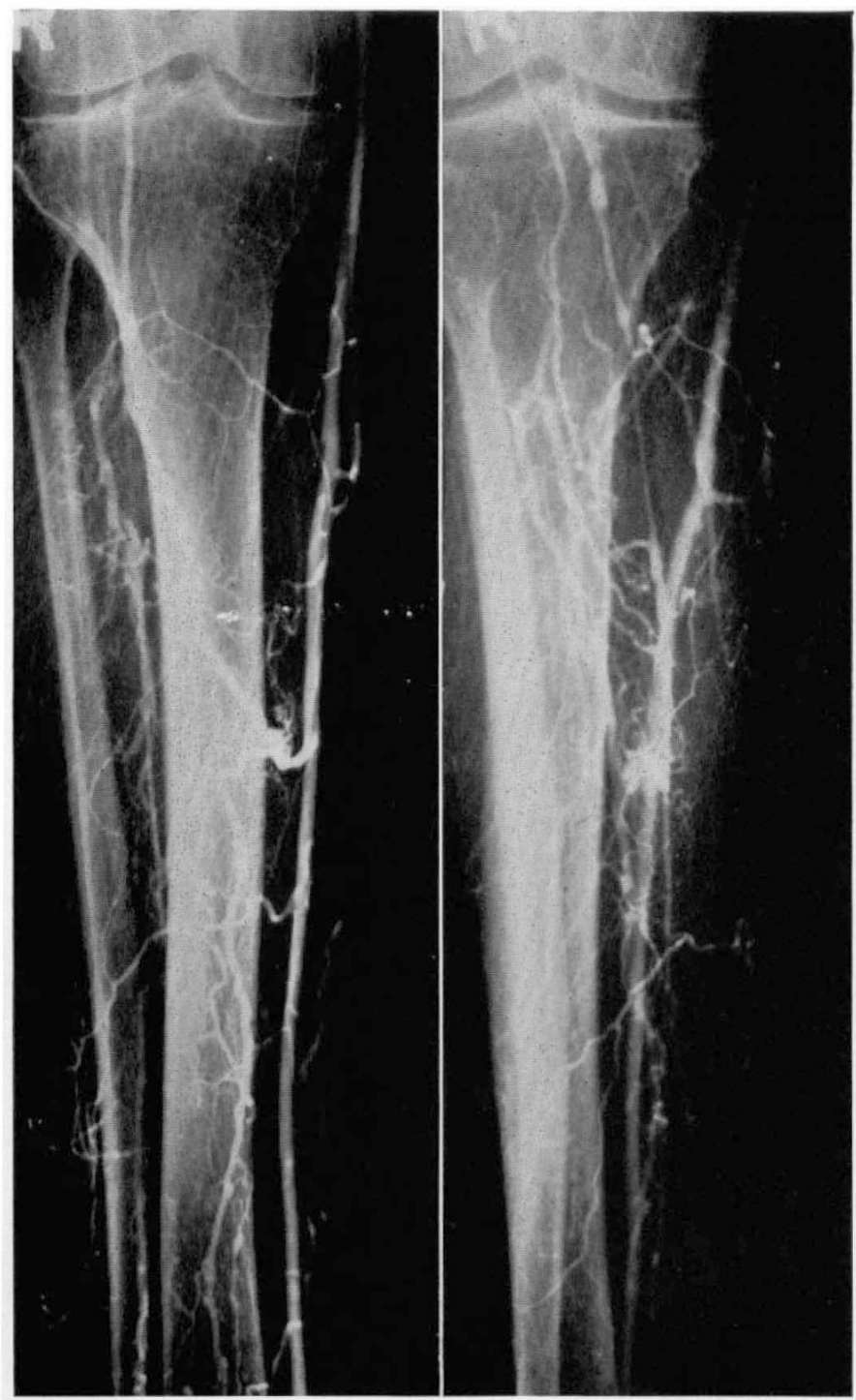

Figs. 5 and 6

Phlebograms of Case 2 demonstrating the blocked deep veins of a clinically silent thrombosis in a patient whose opposite lower limb had previously displayed clinical evidence of thrombosis. 


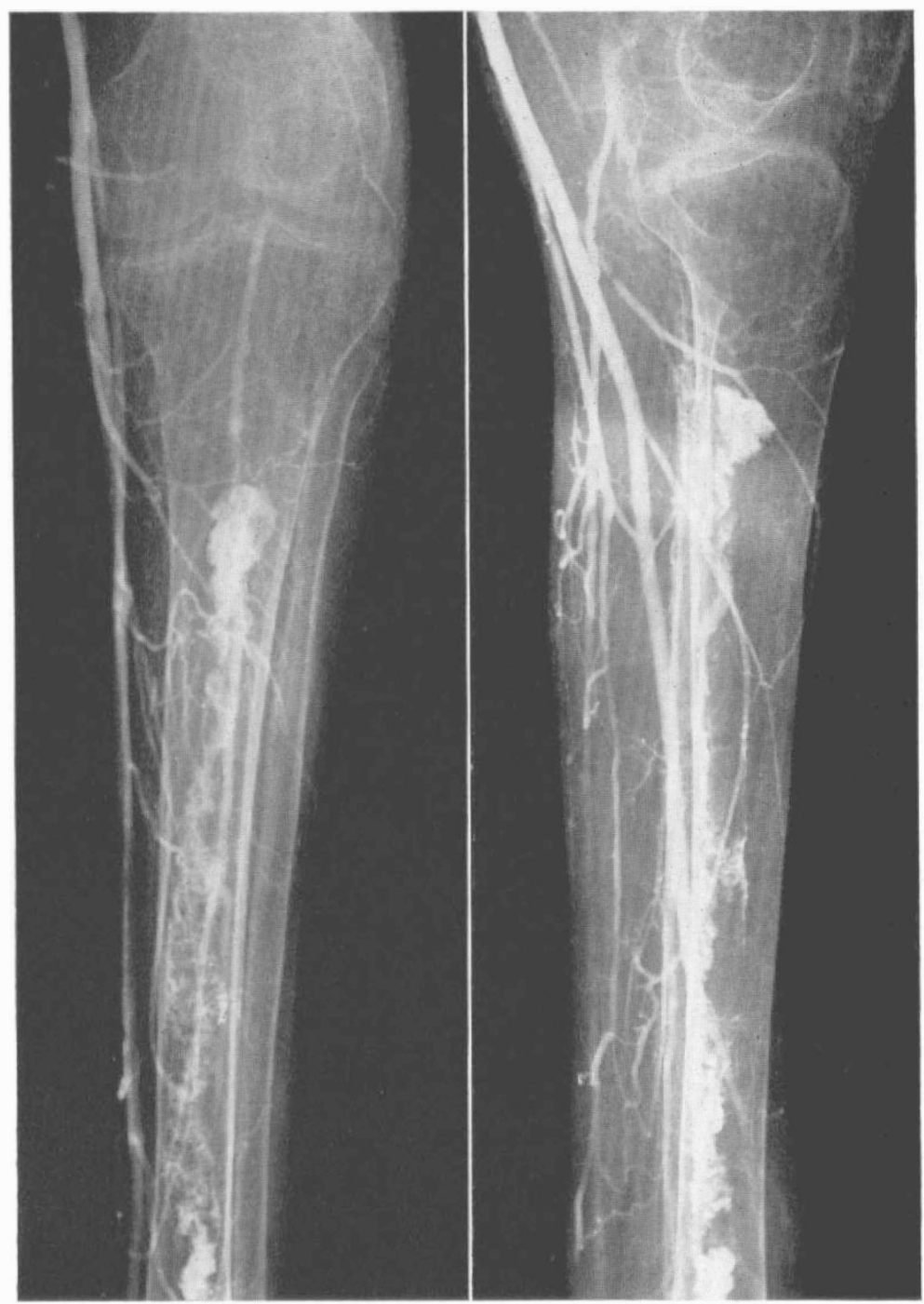

Figs. 7 and 8

Case 3-phlebograms showing absence of deep vein filling-evidence of previous thrombosis. Superficial systems are filling from the intramuscular plexus. 
Case 4. D. S. Male, 26 years old, professional acrobat, fell heavily during his act on 12 April I96I, so sustaining a dislocation of 4 th on the 5 th cervical vertebra. This produced complete, flaccid tetraplegia. Traction by means of Blackburn calipers was commenced and reduction obtained. Motor and sensory function were not regained in the lower limbs. On 9 May 196I pitting oedema of left lower limb was apparent. A diagnosis of deep venous thrombosis was made and anticoagulants commenced. On 26 April I962 the left ankle was still somewhat oedematous. Intravenous phlebograms of the right leg showed patent deep veins but those of the left showed the deep veins to be blocked (figs. 9 and IO).

Case 5. A. McK. Coal miner, 33 years old, sustained a fracture dislocation of the IIth on the I2th dorsal vertebra on 9 January I962. Paraplegia of the lower limbs was complete and has persisted. Reduction and plating was carried out soon after injury. Although there was never, at any time, the suggestion of deep venous thrombosis, at examination on I7 May 1962 he had bilateral ankle oedema. Phlebograms showed failure of filling of the deep calf veins on the left, but on the right were normal (figs. II and I2).

Case 6. G. D. Painter, 50 years old, fell from a height of 40 feet on 4 January I962, so sustaining a fracture dislocation of the Ioth on the I Ith dorsal vertebra. Flaccid paraplegia was complete and has persisted. At no time has there been any clinical evidence of deep venous thrombosis. On 24 May 1962, when examination was undertaken, there was no ankle oedema or ulceration, yet at intraosseous phlebography, there was no deep vein filling in either right or left calf (figs. I3 to I6).

\section{DISCUSSION}

In 1949, Cook and Lyons reported on the very low incidence of venous thrombosis in paraplegics. Forty-five patients were studied radiologically and clinically, and none developed an acute deep venous thrombosis. These authors admit that the factors predisposing to thrombosis are enhanced in such patients. Despite this they believe the low incidence is caused by the comparative youth of patients sustaining injuries severe enough to produce paraplegia. In this present series this age factor appears to be operating in that those patients with no evidence of thrombosis had an average age of 36.6 years, while those with blocked veins averaged $48 \cdot 5$ years.

Bors et al. (1954) investigated 99 paraplegic patients and found at phlebography 58 of these had evidence of venous occlusion. Such occlusion was significantly more frequent in patients with flaccid than in those with spastic paraplegia. One-third of all venous blocks were observed within the first year of injury. Again, this present series claims an incidence of venous thrombosis (I4 per cent.) higher than in general surgical patients, though it hardly approaches that of Bors et al. (1954).

In five patients of the present series the venous occlusion occurred within four months of injury. In five patients (six limbs), muscle power in the calf was completely absent.

Therefore, it seems reasonable to state that in paraplegics a high incidence of deep venous thrombosis can be expected because the calf muscle pump is eliminated and because gravity acts against venous return. The incidence is however lower than might be anticipated because of the comparative youthfulness of these patients. Cook and Lyons (I949) claim that not only does the mast cell population decrease with age, but also the heparin content likewise diminishes. 


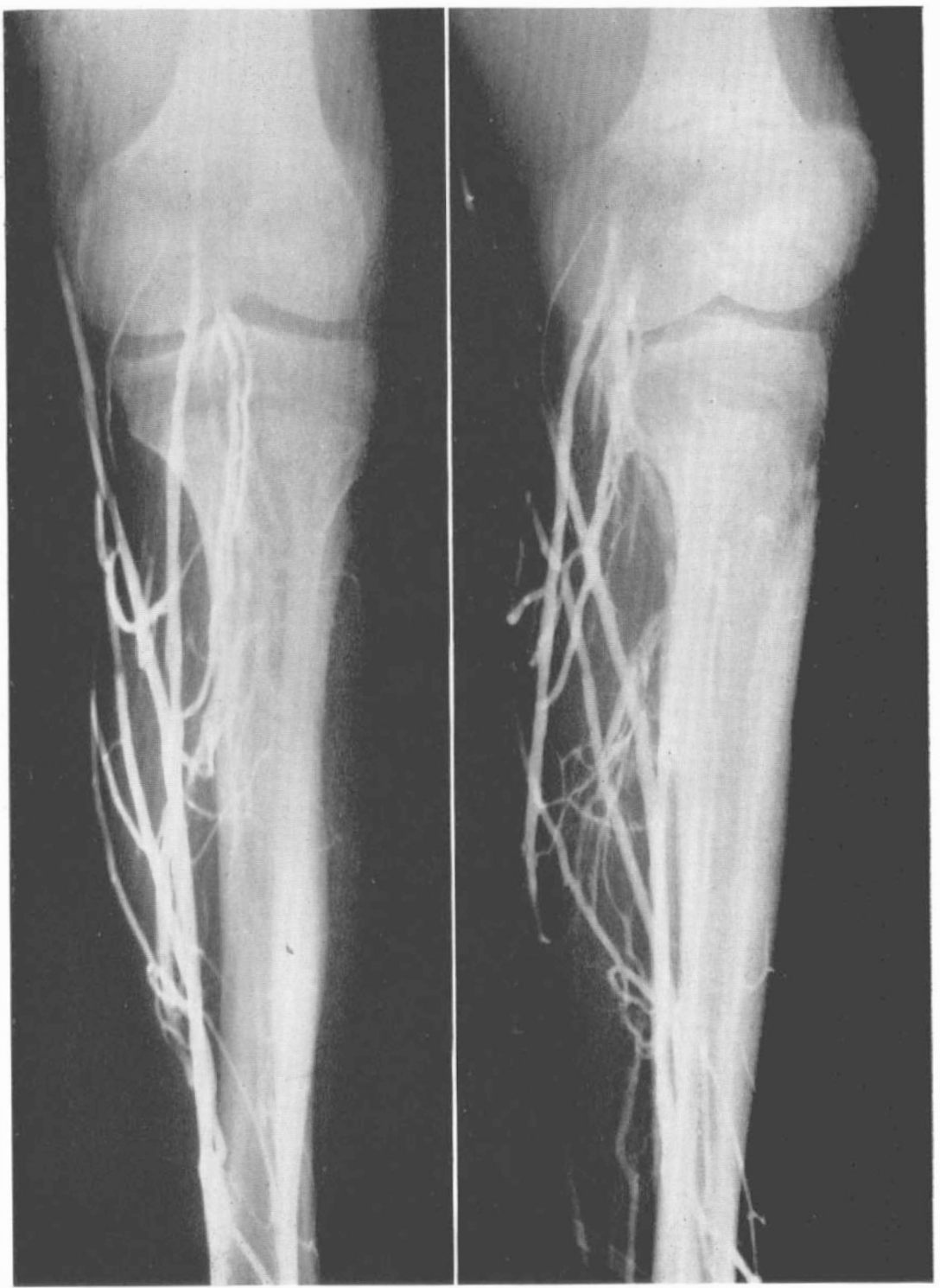

FIGs. 9 and 10

Case 4-popliteal and posterior tibial veins fail to fill. Intermuscular plexus and superficial systems fill well but are not varicose. 


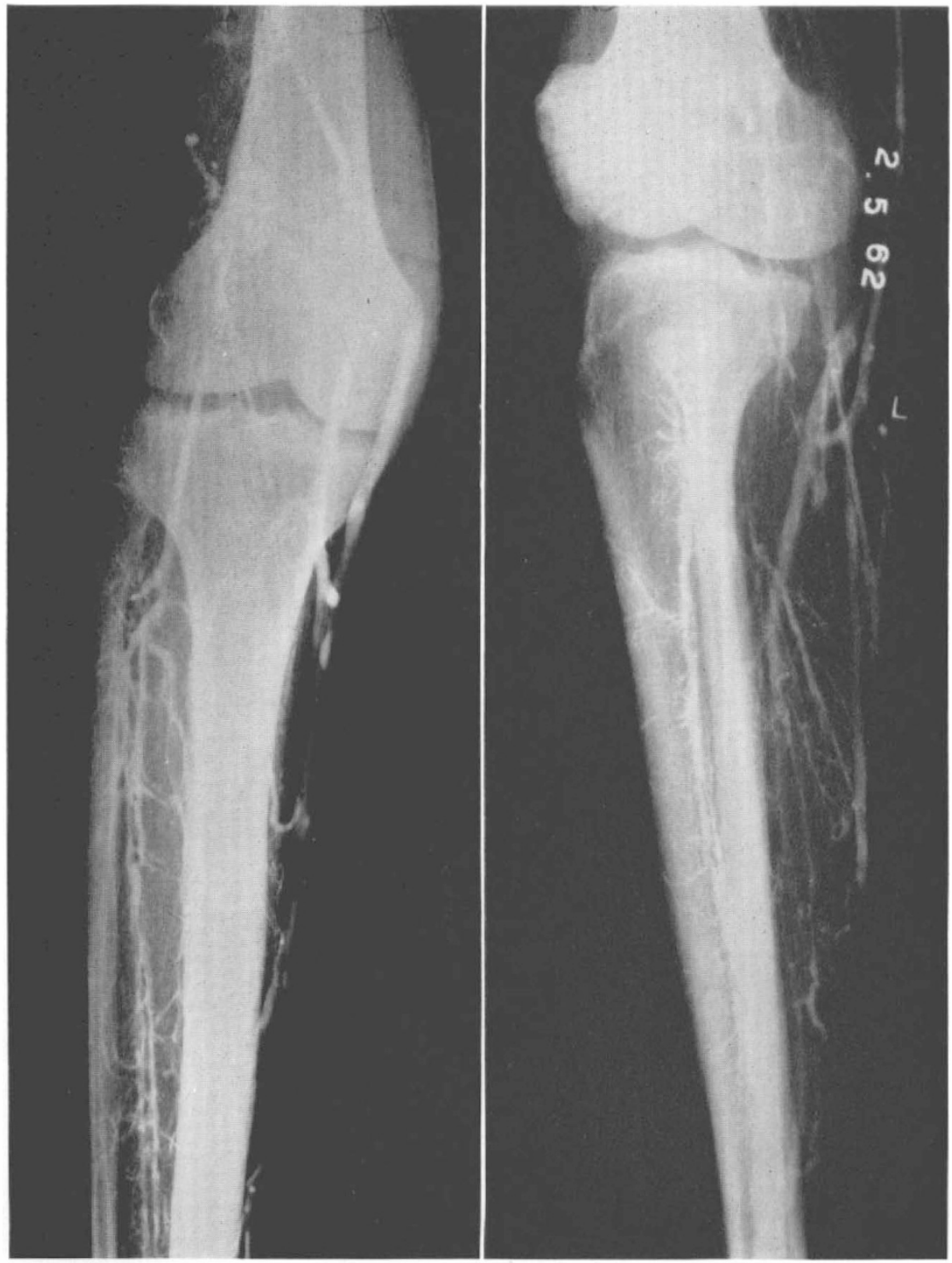

FIGs. II and I2

Phlebograms of Case 5. There are no visible deep veins. Intermuscular plexus and superficial systems are well filled. 


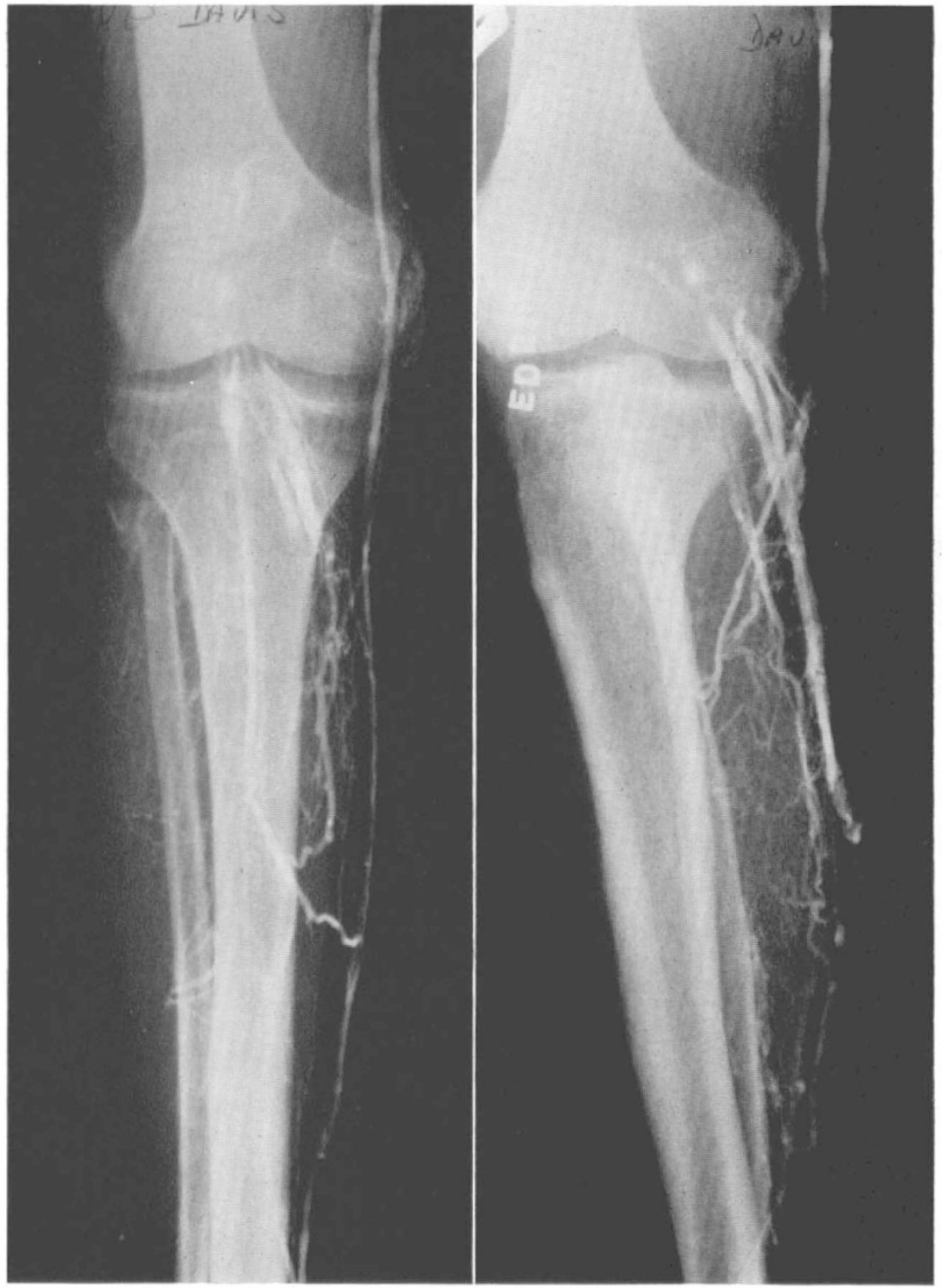

Figs. 13 and 14

Case 6. A bilateral deep venous thrombosis-confirmed by the absence of posterior tibial, peroneal and popliteal veins to fill. 


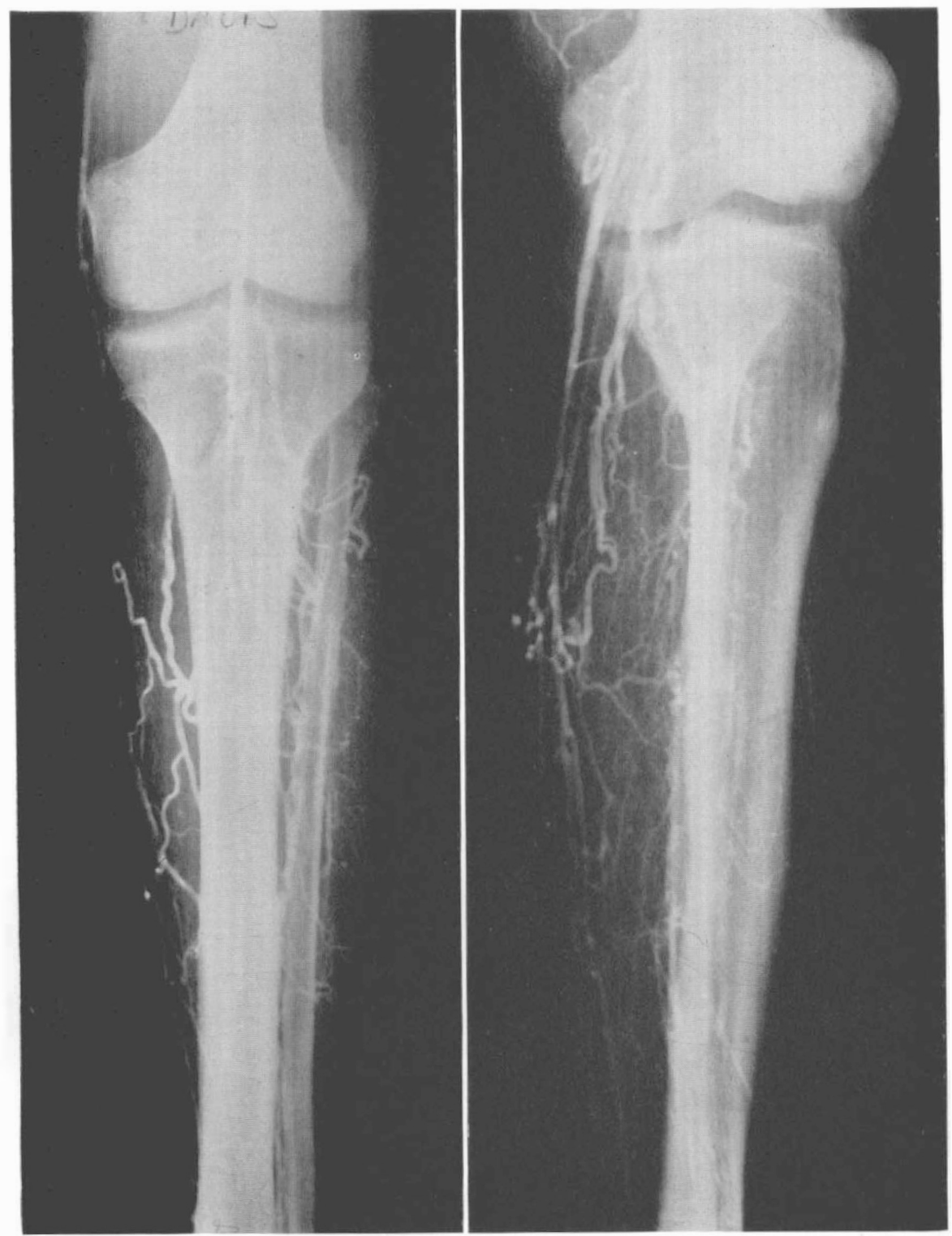

FIGs. I5 and I6

Case 6. A bilateral deep venous thrombosis-confirmed by the absence of posterior tibial, peroneal and popliteal veins to fill. 
An interesting finding, but perhaps one of academic interest, is the absence of a soleal sign in paraplegics. In the normal limb, as the popliteal vein passes deep to the fibrous origin of soleus, the tone in this muscle compresses the vein, producing the apparent filling defect. When the soleus lacks such tone, e.g. in flaccid paraplegia, the vein fills well and the sign is absent.

\section{SUMMARY}

The factors involved in the predisposition to deep venous thrombosis, with their particular application to paraplegia, have been discussed.

Twenty-five paraplegics have been investigated, both clinically and radiologically.

The techniques of phlebography and the interpretation of the resulting films have been briefly described.

The significant phlebographic findings were that in 33 of 50 limbs the normal soleal sign was absent. This has been thought to be due to absence of tone in the soleus muscle.

Seven of the 50 limbs (I 4 per cent.) showed evidence of previous deep venous thrombosis. The relatively high incidence of thrombosis in paraplegics has been discussed in the light of previous published reports.

\section{RÉSUMÉ}

Les facteurs présents dans la prédisposition à la thrombose veineuse profonde, en particulier en relation avec la paraplègie, ont été discutés.

Vingt-cinq paraplègiques ont été étudiés, cliniquement et radiologiquement.

Les techniques de phlébographie et les résultats ont été décrits. Les résultats de la phlébographie montrent que dans 33 des 50 membres éxaminés le signe normal du solèaire était absent, probablement du à l'absence de tonus dans ce muscle.

La présence de thromboses veineuses profondes anterieures a été démontrée chez sept des cinquantes membres éxaminée. L'incidence relativement élevée de la thrombose veineuse chez les paraplègiques a été discutée à la lumière de précèdents articles.

\section{ZUSAMMENFASSUNG}

Die Vorbedingungen für tiefe Venen-Thrombose, und ihre Bedeutung für den Querschnittsgelähmten, werden besprochen.

25 Querschnittsgelähmte sind klinisch und roentgenologisch untersucht.

Die Technik des Phlebogramms und die Interpretation der Roentgenbilder werden kurz beschrieben.

Ein wichtiger phlebographischer Befund war die Abwesenheit des normalen SoleusZeichens in 33 von 50 Gliedmassen. Dies wird durch das Verschwinden des Tonus im M. Soleus erklärt.

Von 50 Gliedmassen zeigten 7 (I4 per cent.), dass eine frühere tiefe Thrombose vorlag. Die verhältnismässig grosse Zahl von Thrombosen bei Querschnittsgelähmten wird mit den Angaben in der Literatur verglichen.

Acknowledgments. I am indebted to the Consultant Staff of the Spinal Injury Unit, Edenhall Hospital, for their permission to investigate their patients.

I also wish to record my thanks to the Staff of the X-ray Departments of Edenhall and Princess Margaret Rose Hospitals. 


\section{REFERENCES}

BAuer, G. (1942). Acta chir. scand., 76, Suppl. 74.

Bors, E., CoNRAD, C. A., \& MAssell, T. B. (I954). Surg. Gynec. Obstet., 99, 45 I.

Cook, A. W., \& Lyons, H. A. (1949). Amer. F. med. Sci., 218, I55.

DodD, H., \& Cockett, F. B. (I956). The Pathology and Surgery of the Veins of the Lower Limb. Edinburgh: Livingstone.

Dos Santos, J. C. (1938). F. int. Chir., 3, 625.

Murley, R. S. (1950). Ann. R. Coll. Surg. Engl., 6, 283.

Pratt, G. H. (1949). Surgical Management of Vascular Diseases. London: Kimpton.

Rowden Foote, R. (1960). Varicose Veins-A Practical Manual. Bristol: Wright.

SCHOBINGER, R. (1960). Angiology, II 283.

Wakin, K. G., Terrier, J. C., Elkins, E. C., \& Krusen, F. H. (I948). Amer. F. Physiol., I53, 183 .

WhitTERIDGe, D. (1954). Edinb. med. F., 61, I. 